\title{
Áreas Protegidas no Interior de Propriedades Rurais: A Questão das APP e RL
}

\author{
Luís Antônio Coimbra Borges, José Luiz Pereira Rezende \\ Departamento de Ciências Florestais, Universidade Federal de Lavras - UFLA
}

\begin{abstract}
RESUMO
As vantagens competitivas do setor agrícola brasileiro influenciam diretamente a expansão da fronteira agropecuária e, consequentemente, a supressão da vegetação natural e alteração dos ecossistemas locais. O presente trabalho visa analisar os diversos aspectos da legislação ambiental para a proteção de áreas no interior das propriedades rurais. As normas legais que tutelam essas áreas foram definidas pelo segundo Código Florestal Brasileiro (Lei 4.771/65). Foram criados espaços representativos dos ecossistemas naturais no interior das propriedades rurais, denominados por Áreas de Preservação Permanente (APP), definidos como intocáveis, e áreas de Reserva Legal (RL), que, uma vez averbados, não podem sofrer o uso alternativo do solo, podendo apenas ser manejados sustentavelmente.
\end{abstract}

Palavras-chave: legislação ambiental, áreas de preservação permanente, reserva legal.

\section{Ambient Protection Areas Inside Rural Properties: The APP and $R L$ Case}

\begin{abstract}
The competitive advantages of the Brazilian agricultural sector directly influence the expansion of the agricultural border and, consequently, the suppression of natural vegetation, modifying the local ecosystems. This work aims to gather, in an only document, the several aspects of the environmental legislation for the protection of areas inside rural properties. The legal norms that rule the areas inside rural properties were defined in the second Brazilian Forest Code, Law \# 4.771/65 - which created representative ecosystem areas inside the properties, denominated Areas of Permanent Preservation, defined as untouchable; and areas of Legal Reservation, which once demarked and protocoled, can only be explored through sustainable management and the alternative use of soil is not allowed.
\end{abstract}

Keywords: environmental legislation, areas of permanent preservation, legal reserves.

\section{INTRODUÇÃO}

A importância do ambiente natural para a vida do homem vem, com o passar dos anos, aumentando a preocupação com a proteção e o uso adequado dos ecossistemas naturais. Sabe-se da importância da edição de normas legais, contudo, apenas elas não fornecem o amparo suficiente para garantir a conservação da natureza. É necessário que haja, também, vontade política voltada à participação 
e divisão de responsabilidades entre os interesses governamentais, comunitários e privados quanto ao uso dos espaços territoriais e da biodiversidade a serem conservados.

O primeiro Código Florestal Brasileiro, datado de 1934, classificava as florestas num todo em quatro categorias: florestas protetoras, remanescentes, modelo e de rendimento. Além desta classificação, foram estabelecidas limitações às propriedades privadas de acordo com a tipologia florestal nela existente e regulada a exploração das florestas de domínio público e privado. Trazia também, a estrutura de fiscalização das atividades florestais, as penas, infrações e as respectivas punições aos infratores (Kengen, 2001). Mesmo assim, era praticamente impossível, à época, monitorar os limites do território brasileiro.

Em 1965, no Segundo Código Florestal, as áreas privadas passaram, também, a ser protegidas por áreas denominadas de Reserva Legal (RL) e Áreas de Preservação Permanente (APP).

As áreas de RL devem ser representativas do ecossistema no qual está inserida uma propriedade, variando de região para região no território brasileiro e, ao contrário das APP, podem ser sujeitas a uso, mediante plano de manejo aprovado pelo órgão ambiental competente, como por exemplo, a agrossilvicultura.

As APP se referem às áreas que devem ser mantidas intocadas, tanto em propriedades públicas, privadas, quanto no interior de cidades, porque se tratam de áreas importantes para a manutenção do equilíbrio ecológico.

O Código Florestal Brasileiro de 1965 passou por várias alterações, sendo a mais recente aquela editada pela Medida Provisória 2.166-67/01. Mesmo assim, ainda permanece a essência do dispositivo original e as inovações apenas trouxeram o engajamento da lei aos interesses e valores da sociedade que mudam com o tempo.

Para entender ao Código Florestal vigente em sua essência, é necessário conhecer o seu princípio básico, contido no seu artigo primeiro (Brasil, 1965).

Art. $1^{\circ}$ As florestas existentes no território nacional e as demais formas de vegetação, reconhecidas de utilidade às terras que revestem, são bens de interesse comum a todos os habitantes do País, exercendo-se os direitos de propriedade, com as limitações que a legislação em geral e especialmente esta Lei estabelecem.

Este artigo considera as florestas e as demais formas de vegetação como um bem público, ou seja, as florestas pertencem ao meio ambiente e devem ser protegidas para a sadia qualidade de vida da população, como descrito na Constituição Federal de 1988. O artigo ainda traz que, no exercício do direito de propriedade, se devem respeitar algumas limitações que a legislação ambiental e especialmente o Código Florestal trazem, como a averbação da RL e a proteção das APP.

Alterações importantes no Código Florestal de 1965 se deram em decorrência da promulgação da Medida Provisória n 2.166-67 de 2001, que acresceu dispositivos e alterou os arts. $1^{\circ}, 4^{\circ}, 14^{\circ}, 16^{\circ}$ e $44^{\circ}$ da Lei. Esta MP foi editada, pela primeira vez, em 1996 (MP 1.511 de 25 de julho de 1996) e reeditada em outras medidas provisórias por mais 66 vezes. Por emenda Constitucional (a de no 32), em 2001, as MP que estavam em vigor, tornaram-se com força de Lei e muitas, até hoje, permanecem em vigência. A partir desta emenda constitucional, as MP criadas não podem mais ser reeditadas. Se não forem transformadas em Lei no tempo limite de 60 dias, perdem seu valor.

O presente trabalho tem como principal característica ser pesquisa exploratória, bibliográfica e documental, elaborada a partir do levantamento e estudo do arranjo legal sobre as áreas protegidas em propriedades rurais no Brasil.

A pesquisa bibliográfica pode ser considerada o primeiro passo de toda a pesquisa científica, pois analisa os vários pontos de vista e oferece uma visão útil, sob o aspecto informativo, do problema em estudo.

Barros \& Lehfeld (1999) complementam este procedimento com o contato e/ou relacionamento com mais pesquisadores para a troca de informações para a elaboração da pesquisa.

Assim, a partir do "estado da arte", que é o estado do conhecimento até onde se conhece sobre $\mathrm{o}$ assunto, realizou-se esta pesquisa com o intuito de esclarecer, de forma crítica e objetiva, e reunir em um único documento, os diversos aspectos da Legislação Ambiental que definem as áreas protegidas no interior das propriedades rurais. 


\section{RESERVA LEGAL}

Como já descrito anteriormente, as áreas de RL são áreas delimitadas no interior da propriedade, representativas do ecossistema no qual estão inseridas e são passíveis de intervenção. Toda propriedade rural deve ter sua RL, obedecendo aos requisitos da lei na região em que se localiza. A área de RL varia de região para região, segundo o Código Florestal de 1965 (Lei 4.771/65) e alterações feitas pela Medida Provisória 2.166-67/01.

A área de Reserva Florestal Legal é definida pela MP 2.166-67/01 como a

[...] área localizada no interior de uma propriedade ou posse rural, excetuada a de preservação permanente, necessária ao uso sustentável dos recursos naturais, à conservação e reabilitação dos processos ecológicos, à conservação da biodiversidade e ao abrigo e proteção de fauna e flora nativas.

A MP 2.166-67/01 também dispõe sobre a reavaliação das porcentagens das áreas de RL em todo o Brasil, a limitação de uso da propriedade, a inalterabilidade de destinação e as condições de se estabelecer e de se recompor o seu percentual.

\subsection{Averbação da Reserva Legal da propriedade rural}

Em acepção ao artigo 225, da Constituição Federal de 1988, a criação de reservas florestais legais e de espaços territorialmente protegidos (Unidades de Conservação) serve como meio de assegurar o meio ambiente ecologicamente equilibrado, exercendo a função de propiciar uma sadia qualidade de vida à população.

O Código Florestal já determina que a área de RL deva ser instituída pelo proprietário da gleba, com a aprovação do órgão ambiental competente. Assim, é inegável a responsabilidade da averbação, pelo proprietário, das referidas áreas de RL.

A gleba deve ser averbada à margem da inscrição da matrícula do imóvel, no registro de imóveis competente, sendo vedada a sua alteração de destinação, nos casos de transmissão, de desmembramento ou de retificação de área. Uma vez averbada, não se altera a destinação da RL.

Os órgãos registradores dos imóveis rurais, os cartórios de registro de imóveis, são obrigados, no momento de transferência de domínio, cumprir a exigência de atendimento aos requisitos do Código Florestal, no que tange à instituição da RL.

\subsection{Tamanho da Reserva Legal}

$\mathrm{O}$ art. 16 da MP 2.166-67/01 diz que as florestas, ou qualquer forma de vegetação, que fazem a cobertura nativa de determinada área, ressalvadas as situadas em APP, são suscetíveis de supressão, desde que sejam mantidas, a título de RL, no mínimo:

I. Oitenta por cento, na propriedade rural situada em área de floresta localizada na Amazônia Legal;

A Amazônia Legal é formada pelos Estados do Acre, Pará, Amazonas, Roraima, Rondônia, Amapá e Mato Grosso e as regiões situadas ao norte do paralelo $13^{\circ} \mathrm{S}$ dos Estados de Tocantins e Goiás, e ao oeste do meridiano de $44^{\circ} \mathrm{W}$ do Estado do Maranhão (Inciso VI, art. $1^{\circ}$, MP 2.166-67/01).

II. Trinta e cinco por cento, na propriedade rural situada em área de cerrado localizado na Amazônia Legal, sendo no mínimo vinte por cento na propriedade $e$ quinze por cento na forma de compensação em outra área, desde que esteja localizada na mesma microbacia.

O Código Florestal de 1965 previa, originalmente, para a região Norte, área de RL de 50\% nas áreas de florestas e de $20 \%$ no cerrado Amazônico. Com a nova redação dada pela MP 2.166-67 de 2001 (art. 16), essas áreas foram alteradas para 80\% e 35\%, respectivamente, isto é, a proteção dos ambientes naturais da região Norte se tornou mais importante.

III. Vinte por cento, na propriedade rural situada em área de floresta ou outras formas de vegetação nativa localizada nas demais regiões do País.

Nas demais regiões do País, ou seja, que não a região Norte, a área de RL corresponde a $20 \%$ da propriedade, valendo, portanto, para qualquer tipo de cobertura vegetal: cerrado, floresta, campo, qualquer cobertura que seja.

$I V$. Vinte por cento, na propriedade rural em área de campos gerais, localizada em qualquer região do País.

Este inciso é redundante, pois, quando comparado com o anterior, trata-se da mesma porcentagem da área da propriedade. O inciso III diz que a RL pode estar situada em área de floresta ou "outras formas" de vegetação nativa. Pode-se deduzir que "outras formas" valham para os campos gerais 
também. Sendo de $20 \%$, a área de RL dos dois itens, bastava o inciso III.

As áreas de RL, independentemente do tamanho e da localização geográfica, devem ser, desde 1965, obrigatoriamente averbadas em qualquer parte do País. No entanto, as restrições se diferenciam no quesito localização. Segundo o Código Florestal, a variação do tamanho da área de RL em cada ecossistema, deverá observar algumas peculiaridades, quer sejam: amazônia legal, cerrado na amazônia legal e as demais regiões do Brasil.

\subsection{Localização da Reserva Legal da propriedade}

A localização da RL deve ser aprovada pelo órgão ambiental estadual competente ou, mediante convênio, pelo órgão ambiental municipal ou outra instituição devidamente habilitada, devendo ser considerados, no processo de aprovação, a função social da propriedade e os seguintes critérios, quando houver:

- O plano de bacia hidrográfica: é importante referenciar a propriedade no seu contexto geográfico, dentro da bacia hidrográfica, e não unicamente;

- O plano diretor municipal: o processo de ocupação urbana deve seguir as normas preconizadas na Lei de Parcelamento e Uso do Solo Urbano (Lei no 6.766/79) e Estatuto das Cidades (Lei $\mathrm{n}^{\circ} 10.257 / 01$ ). As propriedades próximas das áreas urbanas devem merecer maior atenção, pois são mais importantes na recarga do lençol freático e manutenção da vazão dos córregos, que funcionam no abastecimento de água;

- O zoneamento ecológico-econômico: merece ser dada atenção ao processo de ocupação e avanço da agricultura no Brasil. O Zoneamento deve estar correlacionado com a aptidão de uso das terras no Brasil. O Poder Executivo poderá reduzir, para fins de recomposição na Amazônia Legal, a RL para até cinquenta por cento da propriedade. Pode também, ampliar as áreas de RL em até cinquenta em qualquer região do Brasil. Para isso serão ouvidos o CONAMA, o Ministério do Meio Ambiente e o Ministério da Agricultura e do Abastecimento. Este ponto de discussão foi interpretado do $\$ 5^{\circ}$, art. 16 do Código Florestal de 1965, alterado pela MP 2.166-67/01;
- O zoneamento ambiental: criação de Unidades de Conservação da Natureza;

- A proximidade com outra RL, APP, unidade de conservação ou outra área legalmente protegida: evidentemente que, se uma área de RL estiver unida à outra área de proteção, estará contribuindo mais para a maior diversificação, fluxo gênico, enfim, manutenção do equilíbrio do meio ambiente e estará dando uma finalidade mais que correta para a RL (Machado, 2003). Portanto, a legislação não obriga a instituição da RL de maneira contínua, mas tem como meta a averbação de áreas maiores e contíguas. Segundo Maciel (2008), grandes áreas de RL conectadas a APP e a outras áreas protegidas tornam a proteção ambiental mais eficaz, o que permite alcançar com melhor êxito as funções socioambientais previstas no Código Florestal.

\subsection{Procedimento para a averbação da Reserva Legal}

O proprietário deverá, obrigatoriamente, registrar a margem da inscrição de matrícula do imóvel, no registro de imóveis competente, a averbação da RL no interior de sua propriedade.

Para o processo de averbação, o proprietário deverá contratar um profissional habilitado (Engenheiro Florestal, Agrônomo) para elaborar um Laudo de Averbação de RL da propriedade. Este laudo deve ser apresentado ao órgão ambiental e fica a cargo do técnico do órgão ambiental (em MG, por exemplo, o responsável é o IEF) deferir ou não o laudo proposto.

Do laudo deve constar a caracterização da vegetação da propriedade e sua situação de uso. Caso tenha algum fragmento de vegetação nativa no interior da propriedade que esteja próximo de outra área de RL ou APP, este deverá ser proposto para constituir RL, caso não haja, o proprietário deverá seguir alguma das alternativas de recomposição da RL.

Aprovada a averbação da RL pelo órgão ambiental, fica vedada a alteração de sua destinação e o proprietário rural deverá firmar um Termo de Ajustamento de Conduta com o órgão ambiental estadual ou federal competente, contendo a localização da RL, as suas características ecológicas básicas e a proibição de supressão de sua vegetação. 


\subsection{Alternativas de recomposição e compensação da Reserva Legal}

O proprietário, que não tiver a extensão territorial nativa estabelecida pelos critérios que especificam o tamanho da RL nas diversas regiões do Brasil, poderá adotar as seguintes alternativas, isoladas ou conjuntamente:

\subsubsection{Condução da regeneração natural}

A regeneração deve ser autorizada pelo órgão ambiental estadual competente, quando sua viabilidade for comprovada por laudo técnico, podendo ser exigido o isolamento da área.

\subsubsection{Recomposição da RL da propriedade} mediante o plantio, a cada três anos, de no mínimo $1 / 10$ da área total necessária à sua complementação, com espécies nativas, de acordo com critérios estabelecidos pelo órgão ambiental estadual competente

Em MG, por exemplo, o Decreto $n^{\circ} 43.710 / 04$, que regulamenta a Lei Florestal Mineira no ${ }^{\circ} 4.309 / 02$, especifica que a recomposição da RL poderá ser feita num prazo "máximo" de 36 meses (3 anos), apresentando-se mais restritiva que a norma federal. Assim, a recomposição pode ser realizada mediante o plantio com espécies nativas, visando à restauração do ecossistema original.

\subsubsection{Compensação da RL por outra área} equivalente em extensão e importância ecológica, desde que pertença ao mesmo ecossistema e esteja localizada na mesma microbacia onde se situa a propriedade.

$\mathrm{Na}$ impossibilidade de compensação da RL dentro da mesma microbacia hidrográfica, deve o órgão ambiental estadual competente aplicar o critério de maior proximidade possível entre a propriedade desprovida de RL e a área escolhida para compensação, desde que na mesma bacia hidrográfica e no mesmo Estado, atendido, quando houver, o respectivo Plano de Bacia Hidrográfica.

A compensação deverá ser submetida à aprovação pelo órgão ambiental estadual competente, e pode ser implementada mediante o arrendamento de área sob regime de servidão florestal ou RL, ou aquisição de cotas de reserva florestal de outras propriedades representativas da região onde a vegetação exceder os percentuais estabelecidos.

O proprietário rural poderá também, doar ao órgão ambiental competente, área localizada no interior de Parque Nacional ou Estadual, Floresta Nacional, Reserva Extrativista, Reserva Biológica ou Estação Ecológica pendente de regularização fundiária.

Poderá ser instituída ainda, a RL em regime de "CONDOMÍNIO" entre mais de uma propriedade, respeitado o percentual legal em relação a cada imóvel, mediante a aprovação do órgão ambiental estadual competente e as devidas averbações referentes a todos os imóveis envolvidos. O regime de condomínio deve atender a todos os critérios relacionados à extensão, localização e importância ecológica das propriedades averbadas.

\subsection{Limitação do uso da Reserva Legal}

A RL não pode ser suprimida, podendo apenas ser utilizada sob regime de "Manejo Florestal Sustentável”, ou seja, não se pode realizar o corte raso nem o uso alternativo do solo. O corte raso é um tipo de corte em que é feita a derrubada de todas as árvores, de parte ou de todo um povoamento florestal, deixando o terreno momentaneamente livre de cobertura arbórea e sem possibilidade de regeneração para novos manejos. Nas áreas de Reserva, também é vedado o lançamento de agrotóxicos que tenham efeito similar ao de corte raso.

O uso alternativo do solo em que a retirada da vegetação natural é feita para dar lugar a uma nova cultura, é expressamente proibido para as áreas de RL. Portanto, aqueles que utilizarem de forma imprópria a RL poderão ser, segundo a Lei de Crimes Ambientais (Lei 9.605/98), punidos administrativa, civil e penalmente, tendo que arcar com a recuperação do dano, com o pagamento de multas e podendo, o responsável pelo dano (pessoa física ou responsável pela pessoa jurídica), ser preso. Enfim, todos os envolvidos na intervenção sem autorização do órgão ambiental serão responsabilizados, de acordo com o dano causado.

\subsection{Reserva Legal nas pequenas propriedades}

Para assegurar a sobrevivência econômica e social das propriedades e entendendo que sem esta 
sobrevivência econômico-social o meio ambiente é quase que automaticamente depredado, o governo instituiu mecanismos legais que viabilizam o uso da pequena propriedade.

Entende-se por pequena propriedade rural ou posse rural familiar, aquela explorada mediante o trabalho pessoal do posseiro e de sua família, admitida a ajuda eventual de terceiro e cuja renda bruta seja proveniente, no mínimo, em $80 \%$, de atividade agroflorestal ou do extrativismo.

Nestas, no cumprimento da manutenção ou compensação da área de RL, podem ser computados plantios de árvores frutíferas ornamentais ou industriais, ou ainda, espécies exóticas cultivadas em sistema intercalar ou em consórcio com espécies nativas.

Estas propriedades possuem área de, no máximo, cento e cinquenta hectares na Amazônia Legal, cinquenta hectares no polígono das secas e trinta hectares nas demais regiões do País.

A legislação diz que a averbação da RL na pequena propriedade ou posse rural familiar é gratuita, devendo o Poder Público prestar apoio técnico e jurídico, quando se fizer necessário.

\section{8. Área de Preservação Permanente e Reserva Legal}

Áreas de RL e APP são distintas. Enquanto a RL visa conservar parte do ecossistema natural onde a propriedade rural está inserida, a APP visa promover a preservação de certos locais, independentemente da região do País, tais como os topos de morro, as áreas ao longo dos rios, as encostas com declividade acima de $45^{\circ}$, as bordas de chapadas, ao redor de nascentes, entre outros.

Contudo, o Código Florestal, por meio do $\$ 6^{\circ}$, art. 16, alterado pela MP 2.166-67/01, admite o cômputo das áreas relativas à vegetação nativa existente em APP no cálculo do percentual de RL. Este cálculo é permitido desde que não implique em conversão de novas áreas para o uso alternativo do solo e quando a soma da vegetação nativa em APP e RL exceder a:

I. Oitenta por cento da propriedade rural localizada na Amazônia Legal;

II. Cinquenta por cento da propriedade rural localizada nas demais regiões do País;

III. Vinte e cinco por cento da pequena propriedade, cuja área não supere:

a. Cinquenta hectares, se localizada no polígono das secas ou a leste do Meridiano $44^{\circ} \mathrm{W}$, do Estado do Maranhão; $e$

b. Trinta hectares, se localizada em qualquer outra região do País.

Mesmo sendo permitido o cômputo das APP no cálculo da RL, ainda permanece o regime de uso das APP, o qual não se altera, mantendo-se a intocabilidade.

\subsection{Propostas de alteração da Reserva Legal}

As propostas de alteração do Código Florestal Brasileiro estão entre os pontos mais polêmicos e difíceis de serem discutidos no Congresso Nacional. Há, na verdade, interesses distintos entre duas frentes - a bancada ruralista e a ambientalista. Só para se observar o grau de complexidade do tema, foram editadas 67 (sessenta e sete) Medidas Provisórias desde 1996, sendo a sexagésima sétima, considerada como Medida Provisória em transição e com força de Lei (MP 2.166-67 de 2001).

Os anos de 2000 e 2001 foram os mais conturbados no tocante a estas alterações. Primeiro, o CONAMA sugeriu algumas mudanças no conteúdo, tendo na composição da comissão que deliberou o documento pessoas das mais distintas áreas, inclusive da bancada ruralista. Isso gerou um amplo debate com a sociedade. O documento resultante tinha finalidade mais preservacionista, em relação ao Código Florestal original, principalmente no tocante às questões de RL e APP. Segundo, entrou em cena um documento proposto pelo Deputado Federal Moacir Micheletto - guiado pela Confederação Nacional de Agricultura (CNA), no qual defendia os interesses da bancada ruralista. Esta proposta de reformulação do Código Florestal tinha como ponto principal a incorporação das APP (não exploráveis até então) nas RL das propriedades, além da redução da área de RL na Amazônia, que poderia chegar a $20 \%$, se o zoneamento econômicoecológico incluísse a propriedade como apropriada para a agricultura.

Segundo a Sociedade Brasileira de Silvicultura (Sociedade..., 2000), a proposta de alteração do 
Código Florestal, em defesa dos interesses da bancada ruralista, feita pelo Deputado Moacir Micheletto e que reduzia as áreas de RL na região da Amazônia Legal, inicialmente havia sido aprovada. Contudo, prevaleceu no final, por meio da MP 2.166-67 de 2001, a maior preocupação com o meio ambiente ao qual foi dada a devida proteção legal, seguindo as propostas do CONAMA, conforme disposto na Tabela 1.

Segundo Medeiros (2003), a participação do Estado no processo de criação de áreas protegidas no Brasil, em diferentes períodos da história, respondeu às distintas demandas da sociedade, culminando nos dias de hoje com ações conjuntas à defesa da natureza.

\section{3. ÁREAS DE PRESERVAÇÃO PERMANENTE}

APP é a área protegida nos termos dos arts. $2^{\circ} \mathrm{e}$ $3^{\circ}$ do Código Florestal, coberta ou não por vegetação nativa, com a função ambiental de preservar os recursos hídricos, a paisagem, a estabilidade geológica, a biodiversidade, o fluxo gênico de fauna e flora, proteger o solo e assegurar o bem-estar das populações humanas (Brasil, 2001)

As APP são áreas que, de acordo com a sua localização, devem ser mantidas protegidas, não sendo permitido o corte ou a exploração da "floresta" ou da "vegetação" que a cobre, ou mesmo qualquer intervenção, caso não haja cobertura vegetal.

Sobre as APP, o Código Florestal diz o seguinte:

Art. $2^{\circ}$ Consideram-se de preservação permanente, pelo só efeito desta Lei, as florestas e demais formas de vegetação natural situadas:

a. ao longo dos rios ou de qualquer curso d'água desde o seu nivel sazonal mais alto em faixa marginal cuja largura mínima será (Tabela 2):

Estas larguras de áreas ciliares devem ser entendidas para cada margem do curso dágua. Deve-se observar aqui, o entendimento da lei (hermenêutica), que a exigência legal abarca cursos d'água perenes ou intermitentes, naturais ou artificiais.

b. ao redor das lagoas, lagos ou reservatórios d'água naturais ou artificiais;

Como o Código Florestal não especifica qual a área no entorno das lagoas, lagos ou represas que devem ser mantidas a título de "matas ciliares", deixando a questão muito subjetiva, o Conselho Nacional do Meio Ambiente (CONAMA) regulamentou a questão na Resolução a seguir:

Resolução CONAMA n 302, de 20 de março de 2002 (Conselho..., 2002a).

$\mathrm{O}$ art. $3^{\circ}$ desta Resolução diz que constitui APP, a área com largura mínima, em projeção horizontal,

Tabela 2. Larguras das APP em relação às Larguras dos cursos d'água.

Table 2. APP width in relation to watercourses width.

\begin{tabular}{cc|}
$\begin{array}{c}\text { Largura do } \\
\text { curso d'água }(\mathbf{m})\end{array}$ & $\begin{array}{c}\text { Largura da } \\
\mathbf{A P P}(\mathbf{m})\end{array}$ \\
$\leq 10$ & 30 \\
$10-50$ & 50 \\
$50-200$ & 100 \\
$200-600$ & 200 \\
$>600$ & 500 \\
\hline
\end{tabular}

Tabela 1. Alterações do Código Florestal desde 1965 na porcentagem de áreas destinadas a RL.

Table 1. Forestry Code changes since 1965 in percentage of RL areas.

\begin{tabular}{|c|c|c|c|c|c|}
\hline Área & $\begin{array}{c}\text { Código Florestal } \\
\text { de } 1965 \\
(\%)\end{array}$ & $\begin{array}{c}\text { MP do Governo } \\
\text { de } 96-00 \\
(\%)\end{array}$ & $\begin{array}{c}\text { Proposta do } \\
\text { CONAMA } \\
(\%)\end{array}$ & $\begin{array}{l}\text { Proposta dos } \\
\text { ruralistas } \\
(\%)\end{array}$ & $\begin{array}{l}\text { MP em vigor: } \\
2.166-67 \text { de } \\
2001(\%)\end{array}$ \\
\hline Florestas da Amazônia & 50 & $50+30$ & 80 & 50 & 80 \\
\hline Cerrados da Amazônia & 20 & 20 & 35 & 25 & 35 \\
\hline Cerrados fora da Amazônia & 20 & 20 & 20 & 20 & 20 \\
\hline $\begin{array}{l}\text { Florestas e demais formas } \\
\text { de vegetação em qualquer } \\
\text { lugar do País }\end{array}$ & 20 & 20 & 20 & 25 & 20 \\
\hline
\end{tabular}

Fonte: Alterações feitas em quadro da SBS (Sociedade..., 2000). 
no entorno dos reservatórios artificiais, medida a partir do nível máximo normal de:

I - trinta metros para os reservatórios artificiais situados em áreas urbanas consolidadas e cem metros para áreas rurais;

II - quinze metros, no mínimo, para os reservatórios artificiais de geração de energia elétrica com até dez hectares, sem prejuízo da compensação ambiental;

III - quinze metros, no mínimo, para reservatórios artificiais não utilizados em abastecimento público ou geração de energia elétrica, com até vinte hectares de superfície e localizados em área rural.

As discussões que tratam das larguras de áreas ciliares no entorno das lagoas e reservatórios artificiais são as mais polêmicas e, por isso, não são conclusivas, principalmente quando defronte às legislações estaduais que regulamentam tal questão. Em MG, por exemplo, por haver uma quantidade significativa de usinas hidrelétricas que formam grandes reservatórios de água, há muitas discussões sobre o estabelecimento das áreas no seu entorno. A legislação define como APP o espaço que compreende o leito maior sazonal e o ponto em que se permite fazer o uso agrícola da propriedade, que varia entre 30 e $100 \mathrm{~m}$.

Nota-se que a percepção das normas por diferentes juristas pode resultar em interpretações mais ou menos preocupadas com o meio ambiente. Algumas pessoas, mesmo não deixando claro, definem como área ciliar no entorno de reservatórios hidrelétricos $30 \mathrm{~m}$ - interpretação da Lei Florestal Mineira - enquanto a Resolução do CONAMA deixa claro que deverá ser respeitada uma faixa de $100 \mathrm{~m}$. Acredita-se que, em obediência ao espírito da norma de proteção da natureza, deve-se adotar o que fora preconizado naquela que mais protege, instituindo então, uma faixa de $100 \mathrm{~m}$ nos reservatórios artificiais hidrelétricos.

c. nas nascentes, ainda que intermitentes, e nos chamados "olhos d'água", qualquer que seja sua situação topográfica, num raio mínimo de 50 (cinquenta) metros de largura.

Das oito alíneas enumeradas neste artigo, as três primeiras podem ser agrupadas visando à proteção das águas e as outras cinco podem ser consideradas, visando à proteção do solo.

As três primeiras alíneas tratam, especificamente, da proteção das águas e podem ser chamadas, também, por áreas ciliares. Estas são de suma importância para a proteção dos mananciais e cursos d'água. Possuem funções hidrológicas imprescindíveis para sua conservação podendo ser citadas:

- estabilizam a área crítica, que são as ribanceiras dos rios;

- contribuem para a estabilidade térmica dos cursos d'água;

- atuam na diminuição e filtragem do escoamento superficial;

- aumentam a capacidade de recarga do lençol freático;

- impedem a contaminação da água por resíduos tóxicos agrícolas;

- contribuem para a formação de ambientes adequados ao desenvolvimento da fauna aquática e terrestre;

- preservam as espécies florestais raras ou em risco de extinção.

d. no topo de morros, montes, montanhas e serras;

A Resolução CONAMA 303, de 20 de março de 2002, traz algumas definições de alguns termos que podem facilitar o entendimento e a aplicação desta alínea.

Define morro, montanha e linha de cumeada (Conselho..., 2002b):

- Morro: elevação do terreno com cota do topo em relação à base entre 50 e $300 \mathrm{~m}$ e encostas com declividade superior a $30 \%$ (aproximadamente $17^{\circ}$ ) na linha de maior declividade;

- Montanha: elevação do terreno com cota em relação à base superior a $300 \mathrm{~m}$;

- Linha de cumeada: linha que une os pontos mais altos de uma sequência de morros ou de montanhas, constituindo-se no divisor de águas.

Além das definições, a Resolução diz que a APP deve ser no topo de morros e montanhas, em áreas delimitadas a partir da curva de nível correspondente a dois terços da altura mínima da elevação em relação à base. Na ocorrência de dois ou mais morros ou montanhas, cujos cumes estejam separados entre si por distâncias inferiores a $500 \mathrm{~m}$, a APP abrangerá o conjunto de morros ou montanhas, delimitadas a partir da curva de nível correspondente a dois terços da altura em relação à base do morro ou montanha de menor altura do conjunto. 
A Resolução 302 também considera APP as linhas de cumeada, em área delimitada a partir da curva de nível correspondente a dois terços da altura, em relação à base, do pico mais baixo da cumeada, fixando-se a curva de nível para cada segmento da linha de cumeada equivalente a $1000 \mathrm{~m}$. Segundo Borges (2008), a APP em linha de cumeada é aquela que une os pontos que constituem o divisor de águas de uma bacia hidrográfica.

e. as encostas ou partes destas, com declividade superior a $45^{\circ}$, equivalente a $100 \%$ na linha de maior declive.

Nas encostas com declividade superior a $45^{\circ}$ deve-se sempre manter a vegetação intocada, pois a sua retirada proporciona problemas sérios ao solo, como deslizamentos e erosão. Nas áreas urbanas de grandes cidades, o processo de urbanização de encostas é uma questão que tem sido debatida constantemente. $\mathrm{O}$ perigo à vida do homem que ocupa estas áreas é uma realidade mostrada frequentemente nos noticiários, aterrando casas e matando pessoas.

Aliado à proibição de ocupação de uma APP, o poder público precisa disponibilizar uma política de ocupação dos solos, visando à segurança e bemestar da população. O parágrafo único deste artigo especifica o procedimento para as áreas urbanas.

f. nas restingas, como fixadoras de dunas ou estabilizadoras de mangues;

A Resolução CONAMA 303 de 2002 define restinga como depósito arenoso paralelo à linha da costa, de forma geralmente alongada, produzido por processos de sedimentação, onde se encontram diferentes comunidades que recebem influência marinha, também considerada comunidades edáficas por dependerem mais da natureza do substrato do que do clima. A cobertura vegetal das restingas ocorre em mosaicos, e encontra-se em praias, cordões arenosos, dunas e depressões, apresentando, de acordo com o estágio sucessional, estrato herbáceo, arbustivo e arbóreo, este último mais interiorizado.

A APP em restinga, seguindo as instruções desta Resolução, deve respeitar:

a) uma faixa mínima de trezentos metros, medidos a partir da linha de preamar máxima; b) qualquer localização ou extensão, quando recoberta por vegetação com função fixadora de dunas ou estabilizadora de mangues.

g. nas bordas dos tabuleiros ou chapadas, a partir da linha de ruptura do relevo, em faixa nunca inferior a 100 (cem) metros em projeções horizontais.

A Resolução CONAMA 303 de 2002 define tabuleiro ou chapada como paisagem de topografia plana, com declividade média inferior a $10 \%$, aproximadamente $6^{\circ}$ e superfície superior a 10 ha, terminada de forma abrupta em escarpa, caracterizando-se a chapada por grandes superfícies a mais de $600 \mathrm{~m}$ de altitude.

h. em altitude superior a 1.800 (mil e oitocentos) metros, qualquer que seja a vegetação.

No Brasil, as áreas que ultrapassam $1800 \mathrm{~m}$ de altitude, qualquer que seja a cobertura vegetal existente, são consideradas APP, ou seja, são restritas de uso.

Parágrafo Único: No caso de áreas urbanas, assim entendidas as compreendidas nos perímetros urbanos definidos por lei municipal, e nas regiões metropolitanas e aglomerações urbanas, em todo o território abrangido, observar-se-á o disposto nos respectivos planos diretores $e$ leis de uso do solo, respeitados os princípios e limites a que se refere este artigo.

A questão das APP em áreas urbanas está entre as interfaces mais mal trabalhadas na legislação ambiental (Araújo, 2002).

O estabelecimento de limite mínimo menos rigoroso para as áreas urbanas é desaconselhável do ponto de vista do meio ambiente, pois o Código Florestal, segundo Fink (2000), não diferencia as APP em áreas urbanas ou rurais. Por isso, o limite protecionista do Código Florestal deve ser aplicado tanto nas áreas rurais quanto urbanas.

A expressão "limites" constante no parágrafo único define até que ponto o plano diretor poderá ter autonomia para definir a ocupação de uma cidade, desde que respeitadas as legislações ambientais específicas.

Para o entendimento do que seja área urbana consolidada, a Resolução CONAMA 302/02 dispôs a definição bem como os critérios para sua identificação:

Art. 2० Para efeito desta Resolução são adotadas as seguintes definições: 
V - Área Urbana Consolidada: aquela que atende aos seguintes critérios:

a) definição legal pelo Poder Público;

b) existência de, no mínimo, quatro dos seguintes equipamentos de infraestrutura urbana:

1. malha viária com canalização de águas pluviais;

2. rede de abastecimento de água;

3. rede de esgoto;

4. distribuição de energia elétrica e iluminação pública;

5. recolhimento de resíduos sólidos urbanos;

6. tratamento de resíduos sólidos urbanos; e

c) densidade demográfica superior a cinco mil habitantes por $\mathrm{km}^{2}$.

A norma jurídica que institui a responsabilidade de elaboração de um Plano Diretor Municipal vem de 1979, que é a Lei de Parcelamento e Uso do Solo Urbano (Lei 6.766/79), e foi aperfeiçoada pelo Estatuto das Cidades (Lei 10.257/01). Assim, mesmo havendo menor restrição na norma de 1979, prevalecerão as alterações do Código Florestal, uma vez que vale a partir da sua primeira edição, isto é, desde 1965. Marchesan (2008) afirma que as leis municipais, por meio dos planos diretores, não podem fixar padrões inferiores aos limites previstos no parágrafo único do art. $2^{\circ}$ do Código Florestal.

Os municípios que possuem Plano Diretor ficariam responsáveis pela elaboração do plano de uso da bacia hidrográfica e zoneamento econômicoecológico, além da definição dos limites estabelecidos pelo Código Florestal, assim como os casos de uso e intervenção das áreas protegidas. O Plano Diretor deverá ser elaborado a partir de um plano de ocupação da bacia hidrográfica, analisando-se o regime hídrico, a geologia e as atividades econômicas.

Mesmo assim, o grande embate existente entre a preservação e ocupação das APP só teria solução efetiva se houver ação direta dos órgãos de fiscalização, monitoramento e controle (Maciel, 2008).

Ainda são consideradas como APP, as áreas descritas no artigo $3^{\circ}$ do Código Florestal.

Art. $3^{\circ}$ Consideram-se, ainda, de preservação permanente, quando assim declaradas por ato do Poder Público, as florestas e demais formas de vegetação natural destinadas: a. a atenuar a erosão das terras;

b. a fixar as dunas;

c. a formar faixas de proteção ao longo de rodovias e ferrovias;

d. a auxiliar a defesa do território nacional a critério das autoridades militares;

e. a proteger sítios de excepcional beleza ou de valor científico ou histórico;

f. a asilar exemplares da fauna ou flora ameaçados de extinção;

g. a manter o ambiente necessário à vida das populações silvícolas;

h. a assegurar condições de bem-estar público.

$\mathrm{O}$ artigo $3^{\circ}$ do Código Florestal considera APP as áreas que servem de proteção ambiental ou que asseguram o bem-estar da população. O Poder Público poderá instituir ou declarar APP, mediante "Ato do Poder Público", áreas de significativa importância de preservação. Como por exemplo, pode-se citar o entorno de uma voçoroca ou uma floresta de excepcional valor científico. Contudo, o Ato do Poder Público deve especificar a importância da criação de determinada APP.

\subsection{Casos de supressão das Áreas de Proteção Permanente}

O regime de proteção das APP é bastante rígido, especificando que são ambientes que devem ser intocados. Porém, há uma exceção, que é retratada no art. $4^{\circ}$ do Código Florestal alterado pela Medida Provisória 2.166-67 de 2001 (Brasil, 2001).

Art. $4^{\circ}$ A supressão de vegetação em Área de Preservação Permanente somente poderá ser autorizada em caso de utilidade pública ou de interesse social, devidamente caracterizados e motivados em procedimento administrativo próprio, quando inexistir alternativa técnica e locacional ao empreendimento proposto.

$\$ 1^{\circ}$ A supressão de que trata o caput deste artigo dependerá de autorização do órgão ambiental estadual competente, com anuência prévia, quando couber, do órgão federal ou municipal de meio ambiente, ressalvado o disposto no $\$ 2^{\circ}$ deste artigo.

$\$ 2^{\circ}$ A supressão de vegetação em Área de Preservação Permanente situada em área urbana dependerá de autorização do órgão ambiental competente, desde que o município possua conselho de meio ambiente com caráter deliberativo e plano diretor, mediante anuência prévia do órgão ambiental estadual competente fundamentada em 
parecer técnico.

$\$ 3^{\circ} \mathrm{O}$ órgão ambiental competente poderá autorizar a supressão eventual e de baixo impacto ambiental, assim definido em regulamento, da vegetação em Área de Preservação Permanente.

$\$ 4^{\circ} \mathrm{O}$ órgão ambiental competente indicará, previamente à emissão da autorização para a supressão de vegetação em Área de Preservação Permanente, as medidas mitigadoras e compensatórias que deverão ser adotadas pelo empreendedor.

$\$ 5^{\circ}$ A supressão de vegetação nativa protetora de nascentes, ou de dunas e mangues, de que tratam, respectivamente, as alíneas " $c$ " $e$ " $f$ " do art. $2^{\circ}$ deste Código, somente poderá ser autorizada em caso de utilidade pública.

$\$ 6^{\circ} \mathrm{Na}$ implantação de reservatório artificial é obrigatória a desapropriação ou aquisição, pelo empreendedor, das áreas de preservação permanente criadas no seu entorno, cujos parâmetros e regime de uso serão definidos por resolução do CONAMA.

$\$ 7^{\circ} \hat{E}$ permitido o acesso de pessoas e animais às áreas de preservação permanente, para obtenção de água, desde que não exija a supressão e não comprometa a regeneração e a manutenção em longo prazo da vegetação nativa." (NR)

Considera-se de utilidade pública e, ou, interesse social:

(Medida Provisória 2.166-67/2001)

Art. $1^{\circ} . I V-$ utilidade pública:

a) as atividades de segurança nacional e proteção sanitária;

b) as obras essenciais de infraestrutura destinadas aos serviços públicos de transporte, saneamento e energia; e

c) demais obras, planos, atividades ou projetos previstos em resolução do Conselho Nacional de Meio Ambiente - CONAMA;

$\mathrm{V}$ - interesse social:

a) as atividades imprescindíveis à proteção da integridade da vegetação nativa, tais como: prevenção, combate e controle do fogo, controle da erosão, erradicação de invasoras e proteção de plantios com espécies nativas, conforme resolução do CONAMA;

b) as atividades de manejo agroflorestal sustentável praticada na pequena propriedade ou posse rural familiar, que não descaracterizem a cobertura vegetal e não prejudiquem a função ambiental da área; $e$

c) demais obras, planos, atividades ou projetos definidos em Resolução do CONAMA.
Mesmo sendo em área urbana, a supressão da APP depende de aprovação dos órgãos ambientais e somente é permitida em caso de atividade de baixo impacto, mediante plano diretor, dentro dos limites previstos no Código Florestal, não se dispensando as medidas mitigadoras e compensatórias.

Com a disposição da Resolução CONAMA n ${ }^{\circ}$ 369 de 2006 (Conselho..., 2006) foram estabelecidos alguns casos excepcionais para a intervenção em APP. Esta resolução descreve algumas atividades de baixo impacto ambiental que poderão ser realizadas sem estudos técnicos para a intervenção ou supressão proposta.

As atividades de baixo impacto são: abertura de vias de acesso interno e construção de pontes necessárias para a travessia de um curso d’água praticado em pequena propriedade ou posse rural familiar; implantação de trilhas para desenvolvimento de ecoturismo; implantação de corredor de acesso de pessoas e animais para a obtenção de água; construção de rampa de lançamento de barcos e pequeno ancoradouro; construção e manutenção de cercas de divisa de propriedades, entre outros, desde que menor que 5\% (cinco por cento) da APP impactada localizada na posse ou propriedade (Conselho..., 2006).

\subsection{Artigo 18 do Código Florestal}

$\mathrm{O}$ art. 18 do Código Florestal diz que, nas terras de propriedade privada, onde seja necessário o florestamento ou o reflorestamento de APP, se o proprietário não o fizer, o Poder Público Federal poderá fazê-lo sem desapropriar tais áreas.

$\$ 1^{\circ}$ Se tais áreas estiverem sendo utilizadas com culturas, de seu valor deverá ser indenizado o proprietário.

$\$ 2^{\circ}$ As áreas assim utilizadas pelo Poder Público Federal ficam isentas de tributação.

O Poder Público muitas vezes estabelece Leis de difícil implementação, visto que faltam infraestrutura e pessoal treinado para seu cumprimento e implementação. Isto parece ser o caso das APP. Não se tem recurso para promover o florestamento ou o reflorestamento dessas áreas, menos ainda para indenizar os proprietários que as utilizam. A ideia da Lei é boa, mas não se levou em conta sua 
exequibilidade. A legislação ambiental brasileira é uma das mais bem elaboradas, porém, tem pontos incoerentes com a realidade, pois exige da sociedade e das instituições comportamentos e atitudes que elas não conseguem cumprir.

A Lei diz que aqueles que conservam, preservam e recuperam as APP terão preferência em projetos oficiais de assistência técnica, de construção de infraestrutura, como eletrificação rural, estradas e pontes, de créditos rurais e isenção de Imposto Territorial Rural (ITR). Tudo isso fica no campo das boas intenções, pois na prática, não ocorre. $\mathrm{O}$ que existe de significativo nesses incentivos é apenas a isenção do ITR. Porém, os cálculos demonstram que o valor desta isenção é muito pequeno, comparado com o custo de oportunidade de uso dessas áreas, ou seja, o valor por hectare que uma propriedade deixa de recolher de imposto por manter sua APP é menor do que aquele que ela auferiria se explorasse este mesmo hectare com uma atividade agropecuária ou silvicultural.

Nos EUA, os produtores são, além de isentos de impostos, beneficiados por programas de subsídios financeiros e ainda incentivados a adotar planos de manejos estabelecidos por zoneamentos florestais que visem ao uso racional dessas áreas (Valverde et al., 2001).

Por meio da nova concepção mundial de mudança de paradigma do poluidor-pagador para protetor-recebedor, está surgindo, no Brasil, uma nova modalidade de incentivo àqueles que protegem o meio ambiente. Esta modalidade fundamenta-se em critérios de oferta de bens e serviços ambientais que a natureza oferece ao homem. Alguns critérios de pagamento por bens e serviços ambientais já foram estabelecidos e, encontra-se tramitando no Congresso Nacional, um Projeto de Lei (PL 792/07) que institui a Política Nacional de Gestão dos Serviços Ambientais e cria o Programa Nacional de Pagamento por Serviços Ambientais (PNPSA). Ambos preveem incentivos econômicos e financeiros aos produtores rurais que mantiverem protegidas as florestas e estejam contribuindo para a produção de água.

Uma alternativa de benefício ao produtor rural, e que também seria muito bem vinda segundo
Tourinho (2005), é a implementação de um imposto ambiental, no qual toda a sociedade urbana pagaria para a manutenção do meio ambiente. Nesta modalidade de imposto, o produtor rural seria beneficiado com o estabelecimento de áreas protegidas.

\section{CONCLUSÕES}

É obrigação dos proprietários de imóveis rurais, conforme consta do Código Florestal (Lei 4.771/65 e MP 2.166-67/01), a manutenção em suas propriedades das APP e das RL.

As áreas de RL são áreas representativas do ecossistema em que estão inseridas e devem ser preservadas no interior das glebas rurais. As RL poderão ser utilizadas mediante plano de manejo aprovado pelo órgão ambiental, desde que não haja total intervenção, ou seja, não seja feito o uso alternativo do solo.

As áreas de RL, uma vez averbadas, não podem ter sua destinação alterada.

As APP são definidas como intocáveis, podendo sofrer intervenção apenas quando por ato do Poder Público, requerendo utilidade pública, interesse social ou atividade eventual e de baixo impacto ambiental, comprovando-se a inexistência de alternativas técnicas ou locacionais.

A Lei não distingue APP com cobertura ou sem cobertura vegetal. O local estabelecido por lei como APP independe se há ou não vegetação.

A Constituição Federal de 1988 permite aos estados e municípios legislar concorrentemente à união desde que não sejam editadas normas ambientais mais permissivas.

Os incentivos ao produtor rural para a instituição de áreas protegidas no interior das propriedades são justificados pelo caráter coletivo dos bens e serviços ambientais.

\section{STATUS DA SUBMISSÃO}

Recebido: 27/04/2011

Aceito: 19/05/2011

Resumo publicado online: 25/06/2011

Artigo completo publicado: 30/06/2011 


\section{AUTOR (ES) PARA CORRESPONDÊNCIA}

\section{Luís Antônio Coimbra Borges}

Departamento de Ciências Florestais, Universidade Federal de Lavras - UFLA, CP 3037, CEP 37200-000, Lavras, MG, Brasil e-mail: luis.borges@dcf.ufla.br

\section{José Luiz Pereira Rezende}

Departamento de Ciências Florestais, Universidade Federal de Lavras - UFLA, CP 3037, CEP 37200-000, Lavras, MG, Brasil e-mail: jlprezen@dcf.ufla.br

\section{REFERÊNCIAS}

Araújo SMVG. As Áreas de Preservação Permanente e a questão urbana: estudo técnico consultoria legislativa da área de meio ambiente, direito ambiental, organização territorial, desenvolvimento urbano e regional. Brasília: Câmara dos Deputados; 2002. 12 p.

Barros A, Lehfeld N. Projeto de pesquisa: propostas metodológicas. 8rd ed. Petrópolis: Vozes, 1999. 102 p.

Borges, LAC. Aspectos técnicos elegais que fundamentam o estabelecimento das áreas de preservação permanente (app) [tese]. Lavras: Universidade Federal de Lavras; 2008. 192 p.

Brasil. Lei 4.771, de 15 de setembro de 1965. Instituiu o Código Florestal Brasileiro. Diário Oficial da República Federativa do Brasil, Brasília, DF (1965 set. 16). [cited 2008 set. 15]. Available from: https://www.planalto.gov. br.

Brasil. Medida Provisória 2.166-67, de 2001 - Altera os arts. $1^{\circ}, 4^{\circ}, 14,16$ e 44 , e acresce dispositivos à Lei no 4.771. Diário Oficial da República Federativa do Brasil, Brasília, DF (2001 ago. 25). [cited 2008 set. 19]. Available from: https://www.planalto.gov.br.

Conselho Nacional de Meio Ambiente (Brasil). Resolução $n^{\circ}$ 302, de 20 de março de 2002. Dispõe sobre os parâmetros, definições e limites de Áreas de Preservação Permanente de reservatórios artificiais e o regime de uso do entorno. Diário Oficial da República Federativa do Brasil, Brasília, DF (2002a maio 13). [cited 2008 set. 18]. Available from: http://www.mma.gov.br/ conama/.

Conselho Nacional do Meio Ambiente (Brasil). Resolução n 303, de 20 de março de 2002. Dispõe sobre parâmetros, definições e limites de Áreas de Preservação
Permanente. Diário Oficial da República Federativa do Brasil, Brasília, DF (2002b maio 13). [cited 2008 set. 18]. Available from: http://www.mma.gov.br/conama/.

Conselho Nacional do Meio Ambiente (Brasil). Resolução n 369, de 28 de março de 2006. Dispõe sobre os casos excepcionais, de utilidade pública, interesse social ou baixo impacto ambiental, que possibilitam a intervenção ou supressão de vegetação em Área de Preservação Permanente - APP. Diário Oficial da República Federativa do Brasil, Brasília, DF (2006 mar 29). [cited 2008 set. 25]. Available from: http://www. mma.gov.br/conama/.

Fink DPM. Vegetação de preservação permanente e área urbana: uma interpretação do parágrafo único do art. $2^{\circ}$ do Código Florestal. Revista de Direito Ambiental 2000; (2):77-90.

Kengen S. A política florestal brasileira: uma perspectiva histórica. In: Anais do Simpósio Ibero-Americano de Gestão E Economia Florestal; 2001; Porto Seguro. Porto Seguro: Série Técnica Instituto de Pesquisas Florestais; 2001. p. 18-34.

Machado PAL. Comentários sobre a Reserva Florestal Legal. Piracicaba: Instituto de Pesquisas e Estudos florestais - IPEF; 2003.

Maciel LG. Efetividade e eficácia das reservas legais $e$ áreas de preservação permanente nos cerrados [dissertação]. Brasília: Universidade de Brasília; 2008. $164 \mathrm{p}$.

Marchesan AMM. As áreas de preservação permanente: avanços e retrocessos desconsiderando a escassez. Porto Alegre: Ministério Público do Estado do Rio Grande do Sul, 2008. [cited 2008 mar. 20]. Available from: http:// www.amprs.org.br/images/PRESER_\%20PERMA_ AVAN_RETROCESSOS.pdf.

Medeiros RJ. A proteção da natureza: das estratégias internacionais e nacionais às demandas locais [tese]. Rio de Janeiro: Universidade Federal do Rio de Janeiro; 2003. 378 p.

Sociedade Brasileira de Silvicultura - SBS. Discussões sobre Área de Preservação Permanente, Reserva Legal e Código Florestal. Jaguaré: SBS; 2000.

Tourinho LAM. O código florestal na pequena propriedade rural: um estudo de caso em três propriedades na microbacia do rio miringuava [dissertação]. Curitiba: Universidade Federal do Paraná; 2005. 82 p.

Valverde SR, Soares TS, Carvalho RMMA, Fonseca EMB. Comparação entre as legislações sobre áreas de preservação permanente do Brasil, Canadá, EUA, Suécia e Finlândia. Belo Horizonte: CEMIG, 2001. 